\title{
Changes to postgraduate medical education in the 21st century 㹰
}

\author{
Author: Mehool Patel ${ }^{\mathrm{A}}$
}

Medicine is a constantly evolving profession, especially with the advent of rapid advances in the scientific base that underpins this vocation. In order to ensure that training in medicine is contemporary with the continuous evolution of the profession, there has been a multitude of changes to postgraduate medical education, particularly in the UK. This article aims to provide an overview of relevant key changes to postgraduate medical education in the UK during the 21st century, including changes to the structure, governance and commissioning of medical education, effects of European Working Time Directive on training, recent recommendations in the Future Hospital Commission report and Shape of training report, and recent requirements for accreditation of medical education trainers. Many of these recommendations will require complex discussions often at organisational levels, hopefully with some realistic and pragmatic solutions for implementation.

KEYWORDS: Postgraduate medical education, structure of training, time for training

\section{Introduction}

Medicine is a dynamic life-long vocation that is based on a delicate combination of an 'imperfect science' and the 'art' of professionalism. Consequently, training in medicine is bound to change over time. The last two decades have witnessed a multitude of changes to postgraduate medical education, particularly in the UK. These changes have been implemented and/or suggested not only to reflect the variable nature of the profession, but also in response to a changing environment in which doctors practise medicine. These drivers for change are related to both patients and doctors. Patient-related drivers include changes in patient demographics (increase in older population), higher patient expectations both in terms of their own health status and the public's expectations of better service from the medical profession. Doctor-related drivers are improvements in medical technology, including the influence of information technology on the profession, complexities of multiprofessional healthcare delivery, for instance greater emphasis on patient safety, and the expectations of the medical professionals themselves in terms of a better work-life balance.

Author: ${ }^{\text {A }}$ consultant physician in general, geriatric and stroke medicine, and director of medical education, Lewisham and Greenwich NHS Trust, London, UK
This article aims to provide an overview of relevant key changes to postgraduate medical education in the UK during the 21st century, detailing changes to the structure, governance and commissioning of medical education, effects of the European Working Time Directive on training, recent recommendations in the Future Hospital Commission report and Shape of training report, and current requirements for accreditation of medical education trainers.

\section{Structure of postgraduate medical training}

Over the last two decades, two major changes have been implemented to improve the structure of postgraduate medical training in the UK and make it more standardised, structured, time-limited and consistent across the nation; these changes were made following the Calman report in $1993^{1}$ and the Donaldson report in $2002 .^{2}$

The Calman report introduced a structured, time-limited higher specialist training with the creation of a specialist registrar grade (later to be replaced by specialty registrar) to replace the historical 'registrar' and 'senior registrar' grades. For the first time, there was a mandatory defined end-point of training (maximum of 7 years), specialists would be awarded a certificate of completion of specialist training (CCST), and all doctors had to be on a General Medical Council (GMC) register of specialists before being able to take up a substantive consultant post. It also indirectly ensured, for the first time, that a doctor was required to have a postgraduate qualification in their chosen specialty (UK-based or equivalent) before being on the register (in order to be appointed to a substantive consultant post). A generic guide to implement this training called the 'orange book' was published in $1998 .^{3}$ This guide enabled training programmes to ensure consistent standardised training was delivered across all regions.

The 'Modernising Medical Careers ${ }^{4}$ initiative was implemented in 2005 following the publication of a report called Unfinished business by the chief medical officer, Sir Liam Donaldson in $2002,{ }^{2}$ which described the unstructured training for senior house officers. The aims of this programme were to define a time-limited well-defined career pathway with defined educational goals and achieve a balance between service and training. Doctors were appointed to a 2-year foundation programme following graduation and thereafter to a seamless specialty training programme. Recruitment and monitoring of quality of training was centralised and competency-based assessments were introduced. Unfortunately, the implementation of the central Medical Training Application System (MTAS) ${ }^{4}$ was fraught with difficulties. It received such political and public disapproval that a public inquiry was undertaken and the Tooke 
report: Aspiring to excellence was published in $2007 .^{5}$ This report made several recommendations including the 'uncoupling' of certain specialties into 'core' training for 2 years and 'higher specialty' training for 5 years. Consequently, the 'gold guide' was first published in 2010 (sixth edition 2016), providing a reference guide to all postgraduate training in the UK. ${ }^{6}$

The foundation programme was critically evaluated in the report commissioned by Medical Education England (MEE) in 2010 - Foundation for excellence. ${ }^{7}$ This report highlighted many positive aspects of the programme including its design, content, safety, and quality. The programme:

$>$ established a credible 2-year UK-wide generic training with a regulator-approved curriculum and a competency-based programme of formative assessment,

$>$ facilitated the development of an educational infrastructure and faculty including foundation schools,

$>$ provided a standardised national programme for entry into postgraduate medical education in which all trainees must achieve a standardised list of generic competencies,

$>$ had a well-defined national curriculum that allows the trainees to be exposed to a range of 48 medical specialties including shortage specialties,

> was the first training programme to embrace the concept of work-based and competency-based assessment and feedback,

$>$ quality was regulated by the GMC through its quality improvement framework (QIF) set out in $2010{ }^{8}$

Conversely, the particular areas of concern that Collins highlighted included: ${ }^{7}$

$>$ lack of clearly articulated and generally accepted purpose of foundation training,

$>$ confusion regarding the role of the foundation trainee and the balance between demands of service provision and requirements of training,

$>$ lack of provision of timely and appropriate careers advice to trainees,

$>$ quantity of formative assessments may be excessive, onerous and under valued,

$>$ lack of flexibility of the programme,

$>$ timing of GMC registration of trainees,

maldistribution of trainees by specialty, including the need to increase placements in the community, psychiatry and long-term conditions.

Subsequently, the Academy of Medical Royal Colleges (AoMRC) was tasked to address these matters and as a result produced the revised foundation programme curriculum in $2012 .{ }^{9}$

\section{Commissioning and delivery of postgraduate medical education}

The Tooke report ${ }^{5}$ also recommended the creation of MEE, an independent NHS body, in 2009. This body would be responsible for governance, including the commissioning and delivery of all postgraduate medical education in England. In 2012, MEE became part of Health Education England (HEE).${ }^{10} \mathrm{HEE}$ is a nondepartmental public body that is responsible for commissioning, delivering and improving training for all healthcare professionals in England and ensuring that the workforce of today and tomorrow has the right numbers, skills, values and behaviours, at the right time and in the right place, thereby supporting the delivery of excellent healthcare and health improvement to the patients and public of England. HEE is a single national body that operates through four national directors (geographical) and 13 statutory local education and training boards (LETBs) that have replaced the traditional postgraduate medical deaneries. These 13 LETBs are East Midlands, East of England, Yorkshire and the Humber, Wessex, Thames Valley, North West London, South London, North Central and East London, Kent, Surrey and Sussex, North East, North West, West Midlands and South West. In many LETBs, such as those in London, the commissioning and delivery of training is further divided by commissioner and provider such that training is commissioned by HEE via LETBs, but the actual delivery of training is managed by lead providers (appointed through a competitive bidding process) and delivered through local education providers.

Commissioning of medical education in Scotland is slightly different to that in England. NHS Education for Scotland (NES) is an education and training body and a special health board within NHS Scotland. It has responsibility for developing and delivering education and training, and maintaining a local perspective through centres in Edinburgh, Glasgow, Dundee, Aberdeen and Inverness. ${ }^{11}$ Medical education in Scotland is commissioned and delivered by NES Medicine, which is a subsection of NES. ${ }^{11}$ The actual management of medical education is by the Scotland deanery, which was created in 2014 from the four previous deaneries in Scotland, and is responsible for all training across four regions: east, north, south-east and west. ${ }^{11}$ The model enables all four regions to work together as part of NES Medicine, ensuring equity of recruitment and management approach. Contrary to the newer processes of multidisciplinary health education commissioning in England and Scotland, medical education in Wales is still confined to the Wales deanery, which is responsible for commissioning, delivery and management of all medical education within Wales. ${ }^{12}$

\section{Governance of postgraduate medical education}

Postgraduate medical education and training in the UK has always been internationally renowned and acclaimed. This excellent reputation is based on having a robust governance structure in place to ensure that the quality of postgraduate training is regularly monitored in a consistent and transparent manner.

At the turn of this century, the UK government felt that the existing mechanisms governing the quality of medical training were not responsive to change, were not able to reflect consistent quality, and lacked transparency and responsiveness to patient care. Furthermore, there was frustration with the apparent power of the medical institutions such as the medical royal colleges, a lack of levers to use for control, and concern about protecting the public from variable standards, which added to the need for change. Consequently, in 2005, the Postgraduate Medical Education and Training Board (PMETB) was established to address concerns about the perceived lack of transparency in medical postgraduate education and the inconsistency in the quality of medical training across the UK. ${ }^{13}$ PMETB was set up as an independent statutory regulatory body to approve all training posts, specialist training curricula and quality assurance of all postgraduate training programmes. ${ }^{13}$ Its functions were subsequently incorporated into the GMC in 2010 so that now only one organisation (the GMC) oversees both undergraduate and postgraduate medical education. ${ }^{14}$ 
In addition, since 2012, the GMC also maintains ongoing revalidation and certification of all medical doctors in the UK.

The GMC monitors the quality of medical education through its QIF set out in 2010. ${ }^{8}$ It conducts an annual survey of both trainees and trainers across various educational and clinical domains, with particular emphasis on patient safety, and bullying and undermining in the workplace. It works in partnership with local LETBs to monitor and improve the quality of medical education through its quality assurance and quality management frameworks.

\section{European Working Time Directive and impact on training}

One of the major factors affecting the traditional apprenticeship (experiential) model of medical training has been the implementation of the European Working Time Directive in 2009. This directive, coupled with Calman reforms, ${ }^{1}$ implies that compared to previous years, trainees are now exposed to training not only for fewer years but also for restricted hours (48 hours maximum) within those fewer years. The Time for training (or 'Temple') report was a comprehensive review of the impact of European Working Time Directive on the quality of training. ${ }^{15}$ The report highlighted the fact that gaps in the newly developed shift-working rotas (as opposed to the traditional on-call model) had resulted in reduced training opportunities because trainees were moved to fill in these gaps, often at short notice. These gaps were particularly frequent in the evening and night shifts, displacing the trainees from their planned supervised training activities. Consequently, there was reduced trainer and trainee interaction, reduced opportunity for continuity of patient care. The trainees were often unsupported and unsupervised especially out of hours, particularly in specialties with high emergency and/or out-of-hour workloads. Nevertheless, the report stated that with careful planning, high quality training can be delivered within 48 hours as over 15,000 hours of training were still available to trainees in a 7-year training programme.

Some recommendations of the 'Temple' report were:

$>$ development of a 24/7 service, with consultants more directly and flexibly involved in out-of-hours care,

$>$ making every moment count, planning training carefully and focusing on trainees' needs,

$>$ using the learning opportunities in every clinical situation,

$>$ handovers to be an effective learning experience when supervised by senior staff, preferably consultants,

$>$ simulation and technologically enhanced learning initiatives to be considered as they can provide a safe, controlled environment and accelerate learning,

$>$ clinical services designed and configured to deliver highquality patient care and training,

$>$ reconfiguration or redesign of elective and emergency services,

$>$ establishing an effective multiprofessional hospital at night programme,

$>$ consultants directly involved in training should be clearly identified, recognised, developed and appropriately rewarded, and

> commissioner levers should be strengthened to incentivise training, ensure accountability and reward high quality and innovation.

\section{Future Hospital Commission and medical education}

The Future Hospital Commission report, published in 2013, also has key relevant recommendations to the training of future doctors and service provision with the UK. ${ }^{16}$ This report was produced by the Royal College of Physicians and affects future medical training indirectly through its recommendations on the care of acutely ill medical patients, the organisation of medical services, and the role of physicians and doctors in training across the medical specialties in England and Wales. A major change that this report recommends is the paradigm shift from the late 1980-90s concept of being a higher medical specialty consultant with a secondary interest in internal medicine to being a consultant in internal medicine with a secondary higher specialty interest, thereby bringing back the concept of a 'generalist'. Furthermore, recommendations in this report that may affect medical training directly include increasing the need to develop doctors with the knowledge and skills to manage the current and future demographic of patients; the ability to diagnose, manage and coordinate continuing care for the increasing number of patients with multiple and complex conditions; participation in general internal medicine training to become mandatory for those training in all medical specialties; promoting equality in general internal medicine stature, and the contribution of medical registrars will be valued and supported by increased participation in acute services and ward-level care across all medical trainees and consultants, and piloting leadership initiatives in all acute hospitals by introducing initiatives such as chief medical residents.

\section{Recommendations in the Shape of training report}

The latest report outlining the changes required for the future medical workforce and training was published in 2013 called the Shape of training (or 'Greenaway') report. ${ }^{17}$ This review of postgraduate medical education and training was jointly sponsored by MEE - later subsumed into HEE - the AoMRC, the GMC, the Medical Schools Council, the Conference of Postgraduate Medical Deans of the UK, NES, the Northern Ireland Medical and Dental Training Agency and Wales Deanery. Key messages of this report that are likely to affect future medical training over the next few decades:

$>$ train more doctors who are capable of providing general care in broad specialties across a range of different settings,

$>$ continue to need doctors in more specialised areas to meet local patient and workforce needs,

$>$ postgraduate training should prepare medical graduates to deliver safe and effective general care in broad specialties,

$>$ medicine should be a sustainable career with opportunities for doctors to change roles and specialties throughout their careers,

$>$ local workforce and patient needs should drive opportunities to train in new specialties or to credential in specific areas (concept of credentialing as opposed to completion of training at the end of training programmes),

$>$ consider full registration at graduation, provided there are measures to demonstrate graduates are fit to practise.

There should be a UK-wide delivery group that would oversee the implementation of these recommendations.

\section{New requirements for accreditation of medical trainers}

In accordance with all of the changes in training, greater accountability to the public and profession, and quality assurance frameworks, changes have also been introduced to ensure that the trainers in medical education and training are 'fit for purpose'. In 2012, the GMC introduced phased-in measures to ensure that by July 2016, all consultants who are educational and/or clinical 
supervisors for medical trainees undertake an educational appraisal regularly in addition to their own professional appraisal, and have undertaken training and competency in seven domains of educational training. ${ }^{18}$ These domains have been adopted by the academy of medical educators Framework for the professional development of postgraduate medical supervisors, ${ }^{19}$ and include (i) ensuring safe and effective patient care, (ii) establishing and maintaining an environment for learning, (iii) teaching and facilitating learning, (iv) enhancing learning though assessment, (v) supporting and monitoring educational progress, (vi) guiding personal and professional development, and (vii) continuous professional development as an educator. Most organisations and higher specialty training schemes have already ensured that there are appropriate (including online) courses available for consultants to complete their requisite training and/or demonstrate developmental activities in these domains of medical training.

\section{Conclusion}

Compared with the beginning of this century, the medical profession has witnessed numerous changes in terms of structure of training, governance and commissioning of medical education. While medical training is more standardised and structured with definite outcomes, it is constrained both in terms of years of training and by the European Working Time Directive. Further recommendations have been made in various reports including Future hospital: caring for medical patients ${ }^{16}$ and the Shape of training report. ${ }^{17}$ It is important to note that implementing many of these changes has proven to be quite challenging, particularly because of the limited availability of resources to effect these changes.

As mentioned previously, the implementation of the central $\mathrm{MTAS}^{4}$ was fraught with difficulties and received a lot of political and public disapproval. The foundation programme has now been in place for a decade and, while Collins reported on some of its weaknesses, ${ }^{7}$ overall, it has been viewed quite positively. The recent Shape of training report also recommends the foundation programme to continue with greater emphasis on training in both hospital and community settings. The reduction in the actual number of years of specialist training and the impact of European Working Time Directive has resulted in trainees in several specialties feeling ill prepared to take on senior consultant responsibilities, both in terms of confidence in clinical duties and acquiring the leadership and managerial skills required to take on consultant responsibilities. For example, the Association of Surgeons in Training have stated that they believe 65 hours a week is required to gain the necessary training opportunities, and that $80 \%$ of respondents to a survey they ran would support an opt-out of European Working Time Directive to protect training. ${ }^{20}$

The developments of LETBs and their role in commissioning medical education as a component of a wider health education and workforce agenda has also been quite difficult across different regions. In recent years, it has become important to manage increasing expectations of all multidisciplinary healthcare professionals who potentially 'compete' for resources from the same pot (LETB or HEE). There was also a lot of debate and discord during the process of dismantling historical 'deaneries' and replacing them with LETBs that were quite often geographically different to previous set-ups.

Many of these recommendations will require complex discussions in future, often at organisational and regional levels. These discussions will hopefully help to achieve realistic and pragmatic solutions for the implementation of these changes.
Due consideration should be given to these proposed changes, rather than maintaining the status quo, as the drivers for change described earlier are here to stay.

\section{Conflicts of interest}

The author declares no conflicts of interest.

\section{References}

1 Calman K. Hospital doctors: training for the future. The Report of the working group on specialist training. London: Department of Health, 1993.

2 Donaldson L. Unfinished business: proposals for the reform of the senior house officer grade. London: Department of Health, 2002.

3 Department of Health. A guide to specialist registrar training. London: Department of Health. Available online at http://webarchive. nationalarchives.gov.uk/20130107105354/http:/www.dh.gov.uk/en/ Publicationsandstatistics/Publications/PublicationsPolicyAndGuidance/ DH_4006614 [Accessed 13 April 2016].

4 Department of Health. Modernising medical careers - the next steps: the future shape of foundation, specialist and general practice training programmes. London: Department of Health, 2004. Available online at http://webarchive.nationalarchives.gov.uk/20130107105354/http:/dh.gov. uk/prod_consum_dh/groups/dh_digitalassets/@dh/@en/documents/ digitalasset/dh_4079532.pdf [Accessed 13 April 2016].

5 Tooke J. Aspiring to excellence: findings and recommendations of the independent inquiry into modernising medical careers. London: MMC Inquiry, 2008.

6 Conference Of Postgraduate Medical Deans. A reference guide for postgraduate specialty training in the UK ('gold guide'), 6th edn. London: Academy of Medical Royal Colleges, 2016.

7 Collins J. Foundation for excellence - an evaluation of the foundation programme. Medical Education England, 2010.

8 General Medical Council. Quality improvement framework. London: GMC, 2010

9 The Foundation Programme. FP Curriculum 2012. Birmingham: UK Foundation Programme, 2012.

10 Health Education England. Available online at https://hee.nhs.uk/ [Accessed 13 April 2016].

11 NHS Education for Scotland. Available online at www.nes.scot.nhs.uk [Accessed 13 April 2016].

12 Wales Deanery. Available online at www.walesdeanery.org/deaneryhomepage [Accessed 13 April 2016].

13 The General and Specialist Medical Practice (Education, Training and Qualifications) Order 2003. No 1250.

14 General Medical Council. Standards for curricula and assessment systemts merger with PMETB. London: GMC. Available online at www.gmc-uk. org/education/postgraduate/26724.asp [Accessed 13 April 2016].

15 Temple J. Time for training: a review of the impact of the European Working Time Directive on the quality of training. Medical Education England, 2010.

16 Future Hospital Commission. Future hospital: caring for medical patients. London: RCP, 2013.

17 Greenaway D. Securing the future of excellent patient care. London: Shape of Training, 2013.

18 General Medical Council. Recognising and approving trainers: the implementation plan. London: GMC, 2012.

19 Academy of Medical Educators. A Framework for the Professional Development of Postgraduate Medical Supervisors. Cardiff: AoME, 2009. Available online at http://www.medicaleducators.org/write/ MediaManager/A_framework_for_the_professional_development of_postgraduate_medical_supervisors.pdf [Accessed 21 June 2016]

20 Association of Surgeons in Training. Optimising working hours to provide quality in training and patient safety. London: AsiT, 2009.

Address for correspondence: Dr M Patel, Stroke and Elderly Medicine department, University Hospital Lewisham, Lewisham \& Greenwish NHS Trust, Lewisham High Street, Lewisham, London SE13 6LH, UK. Email: mehool.patel@nhs.net 